OPEN ACCESS

Edited by:

Alfrendo Satyanaga,

Nazarbayev University, Kazakhstan

Reviewed by:

Yongmin Kim,

University of Glasgow,

United Kingdom

Abdul Halim Hamdany,

Nanyang Technological University,

Singapore

${ }^{*}$ Correspondence:

Robby Yussac Tallar

robbyyussac@yahoo.com

robby.yt@eng.maranatha.edu

Specialty section:

This article was submitted to

Freshwater Science,

a section of the journal

Frontiers in Environmental Science

Received: 31 December 2021

Accepted: 31 January 2022

Published: 25 February 2022

Citation:

Tallar RY and Geldoffer GM (2022) A Micro-Scale Study of Flood Risk Assessment in Urban Fluvial Areas Using the Flood Potential Index. Front. Environ. Sci. 10:846450. doi: 10.3389/fenvs.2022.846450

\section{A Micro-Scale Study of Flood Risk Assessment in Urban Fluvial Areas Using the Flood Potential Index}

\author{
Robby Yussac Tallar* and Golan Mauregar Geldoffer \\ Department of Civil Engineering, Universitas Kristen Maranatha (Maranatha Christian University), Bandung, Indonesia
}

Worldwide, increasing various methods are being offered to solve the issue of flood disasters in urban fluvial areas, yet there is a relative lack of micro-scale studies concerning the flood potential index (FPI) to forecast future flood events in DKI Jakarta. With recent advances, the information of flood risk assessment can be monitored and communicated by using FPI embedded with a geographical information system (GIS)-based model. Therefore, the main purpose and concerned issue in this paper is how to relate the micro-scale study of flood risk assessment in the urban fluvial area in DKI Jakarta as the study case using FPI. Specific parameters were selected to develop and analyze FPI, involving three considerations: meteorological, physical-environment, and socio-economic aspects. The classification has also been developed by the analysis of data from rainfall, normalized difference vegetation index (NDVI) obtained from Landsat eight interpretation, and population density to produce a flood potential hazard map for each sub-district in DKI Jakarta during 2021-2024. The results of the completed analysis of classification for each sub-district in DKI Jakarta showed 10 subdistricts with high potential, 219 sub-districts with medium potential, and 32 sub-districts with low potential in 2024. Our findings also confirmed that using a GIS approach in identifying and measuring the FPI in DKI Jakarta for micro-scale areas is very helpful in order to develop better adaptive local flood management practices. For future works, the assessment not only produces a visualization of the flood potential index but also estimates possible damage due to the flood hazard itself.

Keywords: flood potential index, GIS, micro scale study, risk assessment, urban fluvial area

\section{INTRODUCTION}

Similar to many metropolitan cities around the world, DKI Jakarta is dealing with flood disasters. According to the previous report from Meteorological, Climatological, and Geophysical Agency of Indonesia (BMKG), DKI Jakarta has been recorded to have extreme floods, which have occurred in 2002, 2007, 2013, 2015, 2016, and the last in 2020. As the occurrence of flood events has become common, the number of flood risk assessments is increasing (Nastiti et al., 2015). Concerning these issues, various methods are being offered by using geographical information system (GIS)-based model applications in order to solve flood risk assessments in large-scale studies (Singh, 2019; Song et al., 2017; Valencia et al., 2020; Zhang $\mathrm{H}$ et al., 2019) and the relationships to the position of the groundwater table (Al Adaileh et al., 2019; Freitas 2016; Nistor et al., 2019; Olaniyi Oke, 2018; Suryawan et al., 2019; Syarif et al., 2013; Wu et al., 2011). Another method is by using the water index in order to describe or analyze water-related problems (Tallar and Dhian, 2021; Nayak et al., 2020; Wang et al., 2020; 
Williams et al., 2019; Tallar and Suen, 2015; Tallar and Suen, 2016). Therefore, many studies have also combined the water index with a GIS-based model (Kawo and Karuppannan, 2018; Taloor et al., 2020), and further studies developed a flood index by using a GIS based-model (Yang et al., 2017; Zhang Y et al., 2019). Although improved tools and models have been used to analyze data concerning flood events, there is a relative lack of micro-scale studies concerning flood risk assessment combined with the flood potential index (FPI) to forecast future flood events in DKI Jakarta. Therefore, the main purpose and concerned issue in this paper is how to relate the micro-scale study of flood risk assessment in DKI Jakarta as the study case by using FPI. This paper presented the development of FPI as well as a flood potential hazard map for each sub-district in DKI Jakarta during 2021-2024.

\section{MATERIALS AND METHODS}

\section{Description of the Study Area}

This research was carried out in DKI Jakarta, the capital city of Indonesia, located at $5,019^{\prime} 12^{\prime \prime} \mathrm{SL}-6023^{\prime} 54^{\prime \prime}$ SL dan $106,022^{\prime}$ $42^{\prime \prime}$ EL- $106058^{\prime} 18^{\prime \prime} \mathrm{EL}$ with an average height of $\pm 7 \mathrm{~m}$ above the mean sea level (MSL). The western boundary of DKI Jakarta is Banten Province, and in the south and east, it is bordered by West Java Province. Administratively, DKI Jakarta is divided into five regions consisting of 42 districts and 261 sub-districts in total. The area of DKI Jakarta is $7,660 \mathrm{~km}^{2}$, with a land area of $662 \mathrm{~km}^{2}$ and a sea area of $6,998 \mathrm{~km}^{2}$. The northern boundary of DKI Jakarta includes $32 \mathrm{~km}$ of coast, which is the source of 13 rivers, 2 canals, and 2 floodways. DKI Jakarta has a tropical climate with an average annual precipitation of $1.755 \mathrm{~mm}$ or about $146 \mathrm{~mm}$ per month. This condition causes some areas in DKI Jakarta to be prone to inundation due to high rainfall and high tide. Moreover, the population density is very high. It was recorded that the population in 2021 was more than 10 million residents with a population density of $16,262 / \mathrm{km}^{2}$ or $42,120 / \mathrm{sq} \mathrm{mi}$.

\section{METHODOLOGY}

The FPI was developed by using three parameters: rainfall data, normalized difference vegetation index (NDVI), and population density. The parameters used in this study are considered as the representatives of three main aspects: physical, environmental, and socio-economic aspects. Figure 1 shows that the initial step is to define considered parameters and collect secondary data. The data were collected from rainfall data, NDVI obtained from Landsat eight interpretation, and population density from Central Bureau Statistics of Indonesia (BPS). All the collected data were processed by using ArcGIS software version 10.5 as an application for the digital mapping process with the following steps: scoring, weighting, and overlaying methods. This scoring method gives a score to each parameter in order to determine the level in each classification. These four parameters will be scaled and weighted according to the order of their abilities and

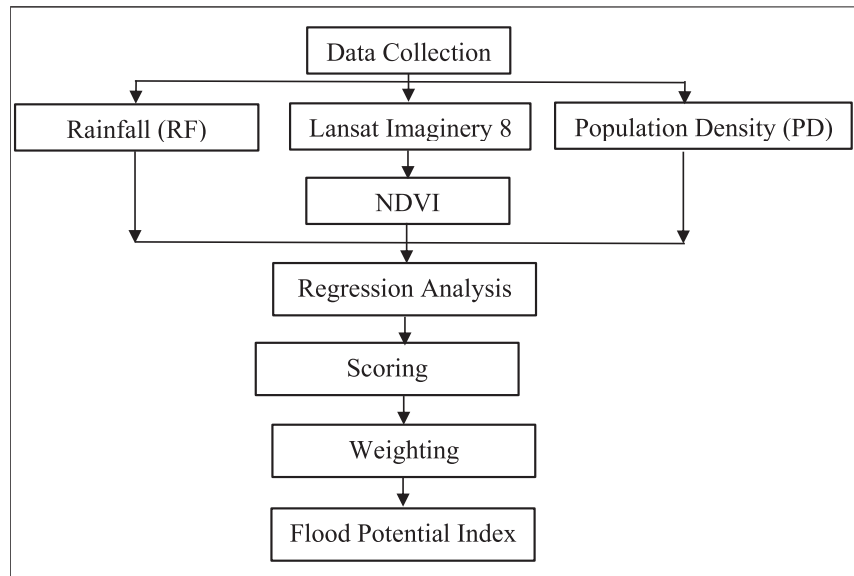

FIGURE 1 | Research flowchart.

conditions of the study area so that the results are obtained in the form of an FPI. In this study, the weighting method of the variables of FPI used is the ranking method. The ranking method is one of the modest methods in assigning weight values of variables by ranking order for each variable (Tallar and Suen, 2016). The class was divided into three classes: high, medium, and low potential. The ranking method was also performed by sorting each parameter used according to the level of importance. The result is an FPI map for DKI Jakarta during 2021-2024.

\section{RESULTS AND DISCUSSION}

One of the most crucial water problems in DKI Jakarta comes from flooding. Recently, there has been extensive map coverage of flood hazard zones in DKI Jakarta; however, it is progressively perceived that flood risk related to natural hazards cannot be reduced solely by focussing on the hazard. Therefore, it is necessary to develop an appropriate method of indexing and mapping flood potential in detail. Despite its significance, previous flood risk assessment methodologies often underestimate levels of vulnerability in areas prone to hazards, yet it is the degree of vulnerability within sub-districts that determines the consequences of any given hazard. The result is an FPI map for DKI Jakarta during 2021-2024 (Figure 2). The results of the completed analysis of classification for each subdistrict in DKI Jakarta showed 10 sub-districts with high potential, 227 sub-districts with medium potential, and 24 sub-districts with low potential in 2021; 12 sub-districts with high potential, 227 sub-districts with medium potential, and 22 sub-districts with low potential in 2022; 10 sub-districts with high potential, 222 sub-districts with medium potential, and 29 sub-districts with low potential in 2023; and 10 sub-districts with high potential, 219 sub-districts with medium potential, and 32 sub-districts with low potential in 2024 (Table 1). Based on the results, there are similarities of FPI in the prone areas of flooding in DKI Jakarta during 2021-2024. Flood mitigation and 


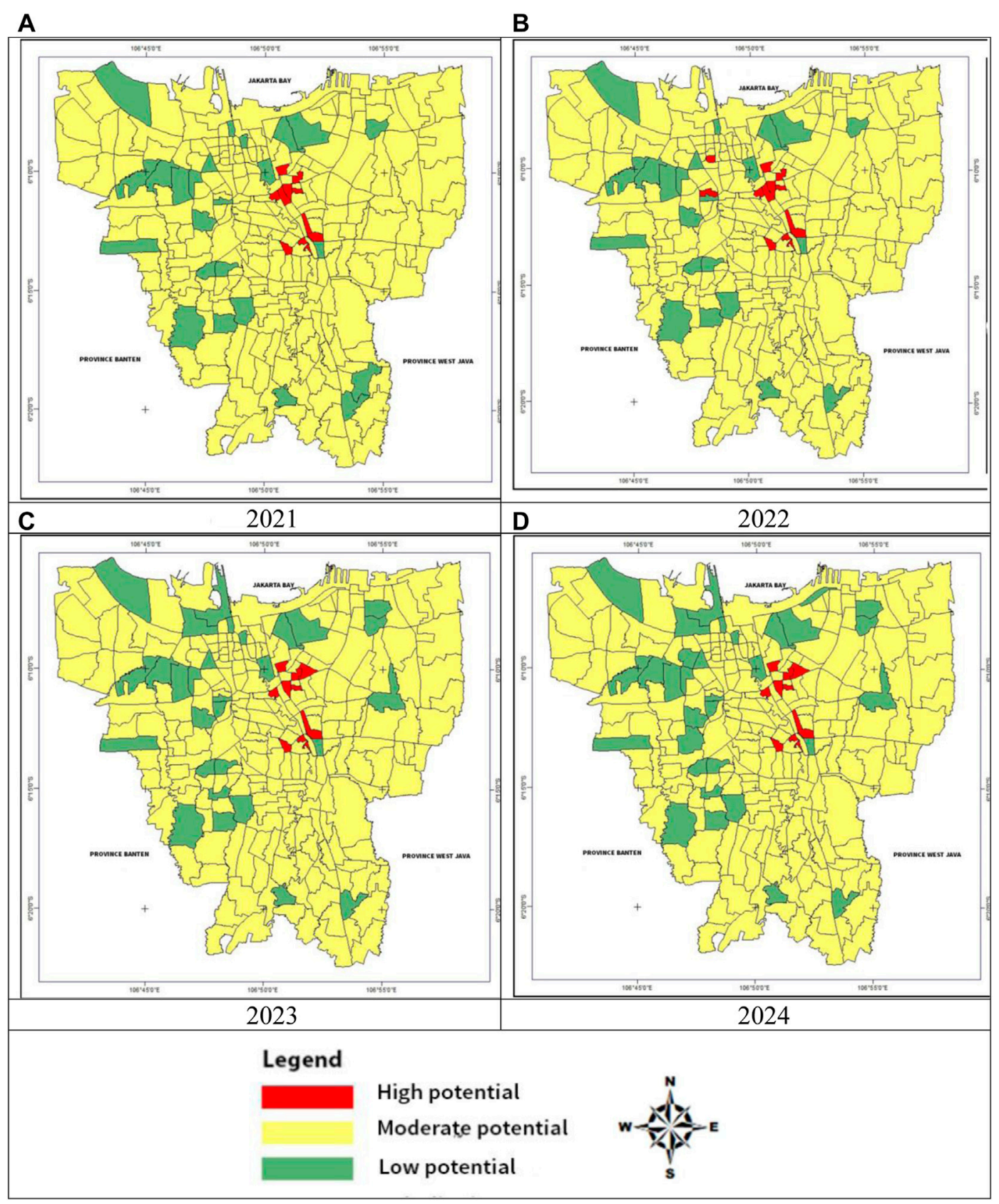

FIGURE 2 | Flood potential index map for DKI Jakarta during 2021-2024.

preparedness programs in the micro-scale should be implemented, such as rainwater harvesting technologies for

TABLE 1 | FPI classification in DKI Jakarta during 2021-2024.

\begin{tabular}{lccc} 
Year & \multicolumn{3}{c}{ Number of sub-districts } \\
\cline { 2 - 4 } & High Potential & Medium Potential & Low Potential \\
\hline 2021 & 10 & 227 & 24 \\
2022 & 12 & 228 & 21 \\
2023 & 10 & 222 & 29 \\
2024 & 10 & 219 & 32
\end{tabular}

each sub-district. DKI Jakarta as an urban fluvial area has executed macro-scale flood mitigation and preparedness programs without considering the relationship between flood characteristics for each sub-district. Moreover, climate changedriven global warming is a factor behind repeated instances of severe flooding across the study area; however, this study proved that flood mitigation and preparedness programs can be implemented in local or micro-scale flood risk assessment. The need of appropriate early warning systems to predict flood characteristics, sufficient databases for assessing flood risk analysis, political will and coordination in local levels of 
government concerning flood problems, and appropriate mitigation programs are several issues that are aims for reducing vulnerability to flood problems in the microscale model.

\section{CONCLUSION}

The study presented proposes a general methodology to assess and map FPI at a detailed, micro-scale level. This captures aspects that are considered crucial and representative of reality (physical, environmental, and socio-economic aspects). These results provide as clear a picture as possible of the reality of the FPI map within DKI Jakarta, leading to a better understanding and guidance for future flood risk management activities in DKI Jakarta. Our findings also confirmed that using a GIS approach in identifying and measuring the FPI in DKI Jakarta for micro-scale areas are very helpful in order to develop better adaptive local flood management practices. It is obvious that the GIS-based method has a great role to play in flood risk assessment because flood is one of many natural hazards with multi-dimensional variables. The FPI had several advantages: 1) a low-cost and micro-scale flood monitoring program that could be used in developing countries and 2) a useful tool for water resource agencies, especially for local agencies, to manage waterbodies and to raise public awareness of flood problems for its data as its data could be easily understood and interpreted. At present, there lacks a framework for monitoring and measuring the flood risk assessment in the micro-scale that enables these institutions to operate and develop and link up the three-

\section{REFERENCES}

Al Adaileh, H., Al Qinna, M., Barta, K., Al-Karablieh, E., Rakonczai, J., and Alobeiaat, A. (2019). A Drought Adaptation Management System for Groundwater Resources Based on Combined Drought Index and Vulnerability Analysis. Earth Syst. Environ. 3 (3), 445-461. doi:10.1007/ s41748-019-00118-9

Freitas, C. R. D. (2016). "Drought," in Natural Hazards in Australasia. Editors C. R. de Freitas and J. Goff (Cambridge: Cambridge University Press), 32-50.

Kawo, N. S., and Karuppannan, S. (2018). Groundwater Quality Assessment Using Water Quality index and GIS Technique in Modjo River Basin, central Ethiopia. J. Afr. Earth Sci. 147, 300-311. doi:10.1016/j.jafrearsci.2018.06.034

Nastiti, K. D., Kim, Y., Jung, K., and An, H. (2015). The Application of RainfallRunoff-Inundation (RRI) Model for Inundation Case in Upper Citarum Watershed, West Java-Indonesia. Proced. Eng. 125, 166-172. doi:10.1016/j. proeng.2015.11.024

Nayak, J. G., Patil, L. G., and Patki, V. K. (2020). Development of Water Quality index for Godavari River (India) Based on Fuzzy Inference System. Groundwater Sustain. Develop. 10, 100350. doi:10.1016/j.gsd.2020.100350

Nistor, M.-M., Rahardjo, H., and Satyanaga, A. (2019). Development Assessment of the Singapore Land: A GIS Spatial-Temporal Approach Based on Land Cover Analysis. Gt 14 (2), 60-73. doi:10.21163/gt_2019.142.06

Nistor, M. M., Rahardjo, H., Satyanaga, A., Hao, K. Z., Xiaosheng, Q., and Sham, A. W. L. (2020). Investigation of Groundwater Table Distribution Using Borehole Piezometer Data Interpolation: Case Study of Singapore. Eng. Geology. 271, 105590. doi:10.1016/j.enggeo.2020.105590 pillar idea of sustainable development: environmental (the idea of staying within a biophysical carrying capacity), social (providing a society constructed on the values that people wish to live by), and economic (providing an adequate material standard of living). For future works, the assessment not only produces a visualization of FPI but also estimates possible damage due to the flood hazard itself; furthermore, the application of FPI can also be implemented in other countries.

\section{DATA AVAILABILITY STATEMENT}

The original contributions presented in the study are included in the article/Supplementary Material, further inquiries can be directed to the corresponding author.

\section{AUTHOR CONTRIBUTIONS}

RT devised the project and the main conceptual ideas and wrote the manuscript. GG worked out almost all the technical details and performed the analysis.

\section{ACKNOWLEDGMENTS}

The authors gratefully acknowledge the support for this research provided by Maranatha Christian University, Indonesia, and under collaboration research with Hydraulics and Ocean Engineering Department, National Cheng Kung University, Taiwan R.O.C.

Olaniyi Oke, M. (2018). Assessment of Meteorological Droughts in Abeokuta, Southwestern, Nigeria. J. Climatol Weather Forecast. 06. doi:10.4172/23322594.1000235

Singh, A. (2019). Remote Sensing and GIS Applications for Municipal Waste Management. J. Environ. Manage. 243, 22-29. doi:10.1016/j.jenvman.2019. 05.017

Song, D., Gao, Z., Zhang, H., Xu, F., Zheng, X., Ai, J., et al. (2017). GIS-based Health Assessment of the marine Ecosystem in Laizhou Bay, China. Mar. Pollut. Bull. 125 (1), 242-249. doi:10.1016/j.marpolbul.2017.08.027

Suryawan, A., Yuliantoro, I., Subarudiand Prayitno, H. (2019). Resilience Process Due to Drougth of El Nino 2015 at Marampit, the Outermost Island of the Indonesia. IOP Conf. Ser. Earth Environ. Sci. 306, 012016. doi:10.1088/1755$1315 / 306 / 1 / 012016$

Syarif, M. M., Barus, B., and Effendy, S. (2013). Penentuan Indeks Bahaya Kekeringan Agro-Hidrologi: Studi Kasus Wilayah Sungai Kariango Sulawesi Selatan. J. Tanah, Lingk, 15 (1), 12-19. doi:10.29244/jitl.15.1.12-19

Tallar, R. Y., and Dhian, B. A. (2021). A Viable Drought Vulnerability index for Outermost Small Islands in Indonesia. Groundwater Sustain. Develop. 15, 100698. doi:10.1016/j.gsd.2021.100698

Tallar, R. Y., and Suen, J.-P. (2016). Aquaculture Water Quality Index: a Low-Cost index to Accelerate Aquaculture Development in Indonesia. Aquacult Int. 24 (1), 295-312. doi:10.1007/s10499-015-9926-3

Tallar, R. Y., and Suen, J.-P. (2015). Identification of Waterbody Status in Indonesia by Using Predictive index Assessment Tool. Int. Soil Water Conservation Res. 3 (3), 224-238. doi:10.1016/j.iswcr.2015.06.009

Taloor, A. K., Pir, R. A., Adimalla, N., Ali, S., Manhas, D. S., Roy, S., et al. (2020). Spring Water Quality and Discharge Assessment in the Basantar Watershed of Jammu Himalaya Using Geographic Information System (GIS) and Water 
Quality Index(WQI). Groundwater Sustain. Develop. 10, 100364. doi:10.1016/j. gsd.2020.100364

Valencia, J., Monserrate, F., Casteleyn, S., Bax, V., Francesconi, W., and Quintero, M. (2020). A GIS-Based Methodological Framework to Identify Superficial Water Sources and Their Corresponding Conduction Paths for Gravity-Driven Irrigation Systems in Developing Countries. Agric. Water Manage. 232, 106048. doi:10.1016/j.agwat.2020.106048

Wang, P., Qiao, W., Wang, Y., Cao, S., and Zhang, Y. (2020). Urban Drought Vulnerability Assessment - A Framework to Integrate Socio-Economic, Physical, and Policy index in a Vulnerability Contribution Analysis. Sustain. Cities Soc. 54, 102004. doi:10.1016/j.scs.2019.102004

Williams, P., Kliskey, A., McCarthy, M., Lammers, R., Alessa, L., and Abatzoglou, J. (2019). Using the Arctic Water Resources Vulnerability index in Assessing and Responding to Environmental Change in Alaskan Communities. Clim. Risk Manage. 23, 19-31. doi:10.1016/j.crm.2018.09.001

Wu, J., He, B., Lü, A., Zhou, L., Liu, M., and Zhao, L. (2011). Quantitative Assessment and Spatial Characteristics Analysis of Agricultural Drought Vulnerability in China. Nat. Hazards 56, 785-801. doi:10.1007/s11069-0109591-9

Yang, M., Xiao, W., Zhao, Y., Li, X., Lu, F., Lu, C., et al. (2017). Assessing Agricultural Drought in the Anthropocene: A Modified Palmer Drought Severity Index. Water 9 (10), 725. doi:10.3390/w9100725
Zhang, H., Xu, Y., and Kanyerere, T. (2019). Site Assessment for MAR through GIS and Modeling in West Coast, South Africa. Water 11 (8), 1646. doi:10.3390/w11081646 Zhang, Y., Huang, S., Huang, Q., Leng, G., Wang, H., and Wang, L. (2019). Assessment of Drought Evolution Characteristics Based on a Nonparametric and Trivariate Integrated Drought index. J. Hydrol. 579, 124230. doi:10.1016/j.jhydrol.2019.124230

Conflict of Interest: The authors declare that the research was conducted in the absence of any commercial or financial relationships that could be construed as a potential conflict of interest.

Publisher's Note: All claims expressed in this article are solely those of the authors and do not necessarily represent those of their affiliated organizations, or those of the publisher, the editors and the reviewers. Any product that may be evaluated in this article, or claim that may be made by its manufacturer, is not guaranteed or endorsed by the publisher.

Copyright () 2022 Tallar and Geldoffer. This is an open-access article distributed under the terms of the Creative Commons Attribution License (CC BY). The use, distribution or reproduction in other forums is permitted, provided the original author(s) and the copyright owner(s) are credited and that the original publication in this journal is cited, in accordance with accepted academic practice. No use, distribution or reproduction is permitted which does not comply with these terms. 